\title{
"PARA QUE LA GENTE SE ENTEREN" LA CONCORDANCIA $A D$ SENSUM EN ESPAÑOL ORAL
}

\author{
Carlos Sánchez Avendaño
}

\begin{abstract}
RESUMEN
En este artículo se describe el fenómeno de la concordancia semántica en dos casos: los sustantivos colectivos y los sujetos formados por un grupo nominal complejo. Se muestra que la concordancia ad sensum no es un descuido o falta de pericia lingüística del hablante, sino una posibilidad de manifestación del sistema gramatical del español, que en unos casos se decanta por la concordancia formal (con criterios morfológicos) y en otros por la concordancia de sentido (por criterios semánticos y textuales).

Palabras clave: gramática del español, concordancia ad sensum, discordancias formales y silepsis, sustantivos colectivos, grupos nominales complejos.
\end{abstract}

\begin{abstract}
This article describes the phenomenon of semantic agreement in two cases: collective nouns and subjects formed by a complex nominal group. It is shown how agreement ad sensum is not a speaker's mistake or a lack of linguistic expertise, but a possibility of Spanish grammatical system, where speakers in some cases choose formal agreement (following morphological criteria) and in others they choose semantic agreement (following semantic and textual criteria).

Key words: Spanish grammar, agreement ad sensum, discordances and silepsis, collective nouns, complex nominal groups.
\end{abstract}

\section{Introducción}

La concordancia es uno de los fenómenos morfosintácticos más llamativos del español para quienes se enfrentan a la descripción de esta lengua o a su aprendizaje como segundo idioma, por cuanto las relaciones que entablan los distintos elementos, tanto en el nivel del grupo nominal como en el de la cláusula, suelen ser constantes y sistemáticas. Por esta razón,

Carlos Sánchez Avendaño. Profesor de la Escuela de Filología, Lingüística y Literatura, Universidad de Costa Rica. San Pedro, San José, Costa Rica.

Correo electrónico: tocumarama@yahoo.com

Recepción: 8- 9- 2008

Aceptación: 24- 9- 2008 
las gramáticas descriptivas de la lengua habitualmente se dedican a detallar el fenómeno y a dar cuenta de los casos anómalos, como la denominada concordancia ad sensum de la que trataremos en este artículo.

No obstante, las descripciones, particularmente en lo que se refiere a las "anomalías", suelen convertirse en una mera casuística, con un tinte prescriptivo variable, sin prestar mayor atención a las causas funcionales que motivan la supuesta discordancia. En este trabajo, nos abocamos a describir, por consiguiente, algunas de estas rupturas de las reglas tradicionales de la concordancia en español, desde la perspectiva de la gramática funcional sistémica y partiendo de nociones gramaticales de índole discursiva.

Con el fin de examinar el funcionamiento de la llamada concordancia ad sensum en muestras de discurso real, recurrimos al corpus de español oral costarricense recopilado por Solano (1989), en el cual se encuentran diversos tipos de secuencias textuales: conversacionales, narrativas, expositivas y argumentativas.

\section{El fenómeno de la concordancia en la gramática del español}

En vista de que, como ya se adelantó, la concordancia suele recibir la atención de la mayoría de las gramáticas del español, sobre todo de las de corte descriptivo y normativo, reseñamos a continuación los principales aspectos que se suelen tratar en relación con este fenómeno.

\subsection{Definición de concordancia}

Los autores del Esbozo de una nueva gramática de la lengua española definen la concordancia como la identidad formal, en determinadas categorías gramaticales, que se verifica entre los elementos de naturaleza nominal y entre el sustantivo y el verbo:

\footnotetext{
La concordancia es en nuestra lengua la igualdad de género y número entre adjetivo o artículo y sustantivo, y la igualdad de número y persona entre el verbo y su sujeto. Con la pérdida de la declinación latina quedaron muy simplificadas las leyes de la concordancia en las lenguas romances, las cuales se limitan al ajuste entre las categorías gramaticales de género, número y persona (Real Academia 1976:386).
}

Esta misma definición se encuentra, con algunas variaciones, en diversas gramáticas sobre el español: Bello (1964), Seco (1960), Gili Gaya (1980), Alcina y Blecua (1994). Las diferencias que se encuentran son sobre todo de orden terminológico, como la denominación de Bello (1964) de la concordancia como "armonía" entre las clases afectadas: del adjetivo con el sustantivo y del verbo con el sujeto. Gili Gaya (1980), por su parte, la concibe como un mecanismo gramatical de relación interna en la oración, consistente en el establecimiento de conexiones formales entre distintas palabras.

Se suele reconocer que el ajuste morfológico se produce en las clases del adjetivo, el pronombre y los determinantes en relación con el sustantivo que sirve de núcleo del grupo nominal, y en el verbo en relación con el sujeto de la cláusula respectiva. Así, por ejemplo, Alarcos (2000) habla de repercusión de las variaciones de género y número en el caso del adjetivo, y sostiene que tales modificaciones no agregan información nueva, sino que se trata de marcas que señalan la relación que entabla el adjetivo con el sustantivo.

Martínez (2000), por su parte, si bien define la concordancia en español como la relación que se establece entre por lo menos dos palabras en cuanto a la repetición de morfemas 
de género, número o persona, y que se produce con el fin de identificar tanto sintáctica como léxicamente las palabras que concuerdan (el adjetivo y el artículo con el sustantivo, el pronombre con el sustantivo y el verbo con el sustantivo o pronombre), se distancia de los autores mencionados en cuanto concibe que la razón de ser de la concordancia es servir como una guía de interpretación y especificación de los distintos elementos del discurso; no se trata, entonces, de un mero índice formal.

\subsection{Las discordancias: silepsis y concordancia ad sensum}

En lo concerniente a la ruptura de la concordancia, Gili Gaya (1980) afirma que las gramáticas, al tratar las anomalías, las reducen a reglas fijas que frecuentemente desembocan en una casuística de escaso valor. Por ello, establece una distinción entre concordancia mentada (la correspondiente al pensamiento del hablante) y la concordancia gramatical (las leyes constantes de expresión); aunque suelen coincidir, entre ambos se pueden producir desajustes debidos a la falta de atención del hablante.

En el Esbozo también se establece una distinción entre concordancia "gramatical" y concordancia "semántica". Si bien para este segundo tipo no emplea esa denominación, de la lectura se colige con facilidad que a esto es a lo que se refiere; sin embargo, fiel a la tradición prescriptiva en la que se inserta, encasilla dentro del segundo tipo discordancias que achaca al descuido o poca experticia del hablante en el manejo del idioma:

\footnotetext{
Estas reglas generales rigen la concordancia gramatical, es decir, la que los hablantes aspiran a realizar según la norma colectiva, más o menos consciente, que la lengua impone a todos como imagen o modelo ideal. Es también, en consecuencia, la que los gramáticos aconsejan como correcta en los casos de duda. Pero en el habla real aparecen a veces desajustes y vacilaciones entre el pensamiento y su expresión, es decir, discordancias gramaticales motivadas, bien por impericia o poco esmero del hablante, o bien por la naturaleza misma del significado y el significante. Por esto, la rapidez improvisadora del habla coloquial favorece la aparición de discordancias, mientras que la expresión escrita fortalece el sentido de la norma gramatical (Real Academia 1976:387).
}

En la lista de discordancias comunes, el Esbozo se refiere a las silepsis, nombre proveniente de la retórica clásica para etiquetar los desajustes morfosintácticos presentes en los textos literarios y, por tanto, legitimados, aunque no por ello aconsejables, según se desprende de la siguiente prevención: "Conviene usar con parsimonia y tino de tales licencias" (Real Academia 1976:388).

Dentro de las silepsis, se incluye la concordancia de los colectivos:

\footnotetext{
a) Cuando el sustantivo es un nombre colectivo y está en singular, el verbo se ha de poner en el mismo número; pero puede usarse en el plural, considerando en el colectivo, no el número singular que representa su forma, sino el de las cosas o personas que incluye (Real Academia 1976: 388), como en el ejemplo: Finalmente, todas las dueñas le sellaron (a Sancho) y otra mucha gente de casa le pellizcaron (Quijote, II, 69).

b) (...) cuando el nombre colectivo venga determinado por un complemento en plural que indique las personas o cosas de que consta el conjunto, es muy común poner el verbo en plural (Ibid:388): Que obligó a que por entonces ninguno de los que escuchándole estaban le tuviesen por loco (Quijote, I, 37).
}

Bello (1964), por su parte, trata con detalle los tipos de silepsis y dedica una de sus anotaciones a los sustantivos colectivos con forma singular, para los cuales existe la posibilidad de que se establezca una concordancia del adjetivo o del verbo en plural, siempre y cuando se cumpla con dos requisitos: significado de colección de elementos de clase indeterminada ("número, multitud, gente, pueblo...") y que el adjetivo o verbo 
no pertenezcan a la misma proposición que el sustantivo. Por estas razones, califica de discordancias inadmisibles las siguientes:

"Habiendo llegado el regimiento a deshora, no se les pudo proporcionar alojamiento"

"El pueblo amotinados"

En el primer caso, la incorrección se debe a que 'regimiento' implica el sentido de colección de individuos de clase determinada (soldados); en el segundo, el error se produce al pertenecer a la misma proposición el sustantivo y el adjetivo, lo cual no sucede en "Amotinóse la gente, pero a la primera descarga de la tropa huyeron despavoridos", pues el verbo subrayado no está incluido en la misma cláusula que 'gente'.

Por último, Bello no expresa reparos con respecto a construcciones del tipo "Cubrían la ciudad por aquel lado una especie de fortificaciones construidas a la ligera", en la que el adjetivo plural concuerda con 'fortificaciones' y no con 'especie', debido a que el sustantivo colectivo se halla modificado por un complemento que especifica los elementos que conforman el conjunto.

En general, los gramáticos suelen seguir a Bello en su explicación sobre las condiciones bajo las cuales se producen los desajustes en la concordancia. Por ejemplo, Gili Gaya concuerda con el filólogo venezolano en que "la indeterminación o heterogeneidad de los individuos que entran en la denominación colectiva favorecen la idea de pluralidad, y por tanto la concordancia de sentido" (Gili Gaya 1980:30), pero difiere de este en cuanto al criterio de la no pertenencia de los elementos a la misma oración, pues sostiene que en realidad lo que importa es la distancia.

Además de tratar con detalle las diferentes relaciones de concordancia que se pueden hallar en español, Martínez (2000) se refiere a los sustantivos colectivos y cuantificativos y a la concordancia según el sentido (concordancia ad sensum). En estos casos, suele suceder que se rompa el acuerdo morfológico entre los diversos componentes y que las categorías que se expresen se atengan más a los contenidos semánticos que a la forma de, por ejemplo, el sustantivo regente, como en los siguientes ejemplos:

Al examen sólo se presentan la mitad de los alumnos

La mayoría de los chicos no asisten a clase

El jurado, presionados unos y apocados los más, declararon inocente al terrorista

En los dos primeros casos, Martínez explica que el núcleo funciona como una estructura cuantificativa partitiva con sentido plural y, además, añade que suelen combinarse con otro sustantivo en plural. En tales casos, Martínez sostiene que en realidad es el sustantivo plural el que actúa como sujeto y de ahí la discordancia aparente con respecto al primer sustantivo.

En el tercer ejemplo, la discordancia del verbo, en cuanto a número, con respecto al sujeto se produce por el sentido plural implícito del sustantivo, fenómeno que se da más frecuentemente cuando existe cierta distancia entre el sujeto y el verbo o cuando algún elemento (un inciso) los separa, como en el caso citado.

A pesar de que el fenómeno parece habitual y corriente en español, el tinte prescriptivo con el que se suele abordar obnubila con frecuencia este hecho, el cual se suele juzgar a partir de reglas de concordancia descontextualizadas y sin asidero en datos de habla real. Así, por ejemplo, Rabanales (1992) califica de discordancias agramaticales, pero aceptadas, casos como los siguientes: La mayoría de los jóvenes insisten en defender su libertad; Finalmente aparecieron la mitad de los libros. 


\title{
3. Estado de la cuestión
}

Pese a que el fenómeno de la concordancia ad sensum se menciona en muchas gramáticas del español, no muchos estudios se han llevado a cabo con el fin de dar cuenta pormenorizada de este en cuanto a su presencia en corpus orales recogidos en conversaciones.

En este sentido, el estudio de Millán (1977) parece ser uno de los pocos que se detienen a detallar las discordancias en discurso real, aunque tampoco ahonda en las posibles causas. Su descripción, basada en parte del total de 175 cintas magnetofónicas que recogen habla culta mexicana, recopila ejemplos de "desviaciones" en relación con las normas de concordancia esperadas, entre ellas las relativas a los sustantivos de sentido colectivo, que son las que nos conciernen aquí:

\begin{abstract}
Es éste [gente] el colectivo que mayor conflicto presenta en el habla mexicana: tolera el uso de adjetivos masculinos no obstante su género etimológico (...), vacila entre el singular y el plural (...), y admite, como ningún otro colectivo, el empleo de plurales en elementos que deberían concordar con él en singular. Esto último sucede cuando es sujeto o forma parte de él en oraciones independientes: "Una serie de gente se han establecido a los largo de la carretera". Y sucede, sobre todo, cuando es antecedente de una oración de relativo: "Hay mucha gente que se cuajaron previamente en el periodismo." Cuando el fenómeno se produce en oraciones adjetivas, parece ser que esta situación se presta al desmembramiento de la pluralidad lógica del colectivo, según puede verse en el ejemplo anterior y en este otro: "Hay mucha gente que han estado acostumbrados a no hacer nada toda su vida."

Cuando entre el sujeto y el verbo de la oración principal irrumpe una de relativo en la que la concordancia del verbo todavía se mantiene, la falta de concordancia numérica entre los elementos de la frase rota se produce por la lejanía existente entre uno y otro (...): "La gente que vive en el mar también lo vieron"; "Antes la gente que estaba inválida se sentaban a llorar; "La gente que está muy pobre, el gobierno les da dinero". Empero, esta ruptura de la concordancia se observa no sólo en esos casos, sino también en muchas otras construcciones, aún más violentas: "Se veían gente de todo tipo"; "Hubieron mucha gente que murió"; "Todos son esfuerzos que han acumulado la gente". Donde, como se ve, la anteposición del verbo debe aunarse a los factores que favorecen la concordancia con la pluralidad lógica (Millán 1977:102-103).
\end{abstract}

En esta misma tónica se refiere a otros sustantivos de sentido colectivo, como 'pareja', 'matrimonio', 'familia', 'juventud':

He advertido, como hecho casi sistemático en el habla, que estas tres palabras [matrimonio, pareja y familia] provocan el empleo del plural en elementos que deberían concordar con ellas en singular. Es obvio que, en el caso de matrimonio y pareja, su carácter dual motiva tal uso: "El matrimonio francés que van a alquilar el departamento"; "Una pareja pueden estar manifestándose cariño mutuo, pero en su ser más íntimo permanecen solos"; "Somos cuatro parejas de matrimonios...bueno, una de ellas no son casados". La palabra familia, sin equivaler a un dual, se siente compuesta por un número de integrantes más o menos determinado, y se toma como una unidad plural, según se aprecia en los siguientes ejemplos: "Les dio el susto de su vida a la familia de A."; "Cualquier familia, por escasos recursos, tienen su radio"; "La verdadera familia no existe cuando son numerosos (Millán 1977:103).

Como se aprecia de los comentarios de Millán, la forma en que se ha abordado el fenómeno de la concordancia en español no suele considerar su función discursiva y por ello se sostiene que existen reglas obligatorias de acuerdo entre las distintas categorías, las cuales no toman en cuenta la descripción morfosintáctica más allá del nivel de la cláusula. Cuando tales reglas no se cumplen, se habla de rupturas, discordancias, silepsis, vacilaciones, descuidos o impericia lingüística. 


\section{La concordancia con los sustantivos de sentido colectivo y de sentido indefinido}

En este apartado, nos abocaremos a describir el funcionamiento de la concordancia en relación con los sustantivos de tipo colectivo en español oral, basándonos en el corpus de habla culta costarricense recogido por Solano (1989). Vale recordar que muchas de las discordancias (en relación con las reglas descontextualizadas de las que hablamos con anterioridad) que se tratarán son precisamente las que han sido registradas en las gramáticas de corte tradicional bajo la denominación de silepsis y, dentro de esta, de la concordancia ad sensum.

El fenómeno de la concordancia con sustantivos como 'gente', 'pueblo', 'multitud' y otros con morfología singular pero con semántica plural no solo se resiste a coincidir con las reglas generalizadoras que se han propuesto para describir su funcionamiento en español, sino que tampoco se trata de casos aislados o propios únicamente de registros espontáneos informales, sino que es común hallarlas en documentos de alta formalidad, como los siguientes dos ejemplos, tomado el primero del informe de un proyecto final de graduación en el nivel de maestría, y el segundo de un artículo de una revista científica:

Es muy importante dedicar tiempo para aclararle al grupo los objetivos del proyecto y motivarlos a tener una buena disposición para trabajar la comprensión oral explicando la importancia de ésta

(...) ellos tenían recursos que les pertenecían y que esos recursos necesitaban conservación. A C A le dijo a la gente que tenían que presionar por el pago de sus recursos

En primera instancia, es necesario detenerse en el concepto mismo de "sentido colectivo". Con este término, se desea expresar en lingüística la falta de correlación entre la semántica y la morfología, pues se indica que un sustantivo, aun teniendo una forma singular, expresa un sentido plural, como se colige de la definición de Lewandowski (2000:59): "Colectivo. Nombre colectivo que, siendo sustantivo singular, comprende una multitud de objetos concretos, p.ej., bosque, rebaño, sierra, equipo." A este respecto, Seco (1960) agrega que esa agrupación contiene individuos de una misma especie.

En este sentido, habría una tipología semántico-morfológica que distinguiría entre sustantivos colectivos (morfología singular y sentido plural) y sustantivos individuales (morfología singular y sentido singular, o morfología plural y sentido plural), dicotomía de hecho explícita en autores como Seco (1960). Sin embargo, las reglas de la concordancia se han formulado tradicionalmente en español atendiendo exclusivamente a la morfología de los sustantivos y, por ello, se habla de discordancias (faltas de concordancia, silepsis, concordancias ad sensum, etc.) cuando la concordancia se atiene más bien a la semántica.

En nuestro criterio, se trata de un error conceptual en la descripción de la morfosintaxis de la lengua, motivada por la poca comprensión de la función (significado) de la concordancia. Si se la estudia como mero requisito formal, que lleva a ajustar la morfología flexiva de los elementos nominales con respecto a su sustantivo regente dentro del grupo nominal y del verbo en relación con su Sujeto regente, es obvio que se pase por alto la razón de su existencia dentro de la lengua. Por el contrario, si asumimos una perspectiva teórica funcional del lenguaje, hemos de dilucidar su valor representacional, textual o interpersonal, en el entendido de que las estructuras y sistemas dentro de una lengua no surgen por capricho o casualidad, sino para cumplir cometidos funcionales muy específicos dentro de las tres esferas mencionadas. 
Estudiar la gramática como un compendio de formas y de reglas sin conexión con el valor comunicativo que los hablantes usuarios de la lengua le asignan constituye una perspectiva típica de la gramática normativa tradicional, lo que ha empañado el entendimiento cabal de su funcionamiento. El caso de la concordancia es un buen ejemplo de este modo de proceder en la descripción lingüística.

Opuesta a esta tradición, la gramática funcional sistémica representada por Halliday (2004) propone la existencia de tres metafunciones que determinan la aparición y especialización de las formas en una lengua, lo cual constituye una forma de conceptualizar la gramática fundamental para entenderla en toda su complejidad. Para la perspectiva sistémica, la funcionalidad es inherente al lenguaje; todas las formas surgen, se relacionan y actúan a partir de este principio, pues las lenguas son como son debido a las funciones que cumplen para los seres humanos. Por todo lo anterior, es común hablar de metafunciones en teoría sistémica con el fin de subrayar que la funcionalidad constituye un componente consustancial e integrado de la teoría.

Dos de estas metafunciones pretenden dar cuenta de la relación entre la forma del lenguaje y el entorno ecológico y social en el que surge, pues este cumple las funciones básicas de dotar de sentido a la experiencia de los hablantes y de permitir y poner en marcha las relaciones sociales. Estas dos funciones se denominan, respectivamente, ideacional e interpersonal.

La metafunción ideacional se refiere al carácter de la lengua como constructora de la experiencia de los seres humanos: su empleo para nombrar y construir categorías que se configuran en patrones gramaticales de todo tipo; de este modo, la experiencia se transforma en significado: se codifican por medios formales las taxonomías, las entidades, las propiedades, la cronología de los eventos, la cantidad de elementos, los procesos, la evidencia en torno a los acontecimientos, etc. Los constituyentes básicos de la cláusula como experiencia son los Participantes, el Proceso y las Circunstancias.

En segundo lugar, la metafunción interpersonal se encarga de la representación de las relaciones interpersonales, de los aspectos que enmarcan nuestra condición de seres que viven en sociedad y deben convivir con otros seres, compartir o enfrentarse a los valores de la comunidad, a su forma de organizar las relaciones, a su manera de concebir los límites de lo adecuado socialmente hablando. Por medio del lenguaje, en suma, interactuamos, intercambiamos (solicitamos y damos) información o bienes, valoramos el acontecer, asumimos una posición con respecto a nuestros interlocutores, emitimos juicios, etc. Algunos de los constituyentes de la cláusula según esta perspectiva son el Sujeto, el Predicador, el Complemento y los Adjuntos.

Si bien es cierto que estas dos metafunciones dan cuenta del hecho de que siempre hablamos sobre algo y con alguien, existe una tercera función en el lenguaje: construir textos. Por medio de la metafunción textual, se posibilitan las otras dos, en tanto construir la experiencia y representar las relaciones sociales son posibles gracias a que un hablante es capaz de construir secuencias discursivas y de organizar el flujo comunicativo por medio de mecanismos textuales.

Uno de estos mecanismos es el conocido como cohesión, el cual se concibe como un fenómeno textual relacionado con marcas patentes introducidas en un texto -oral o escritopara dotarlo de unidad. Por consiguiente, se produce intratextualmente, gracias a una red de enlaces que funcionan en conjunto para establecer la unidad semántica de un texto a partir de las relaciones explícitas entre los elementos que lo componen. 


\title{
Desde la perspectiva de Halliday y Hasan (1997:4):
}

\begin{abstract}
Cohesion occurs where the INTERPRETATION of some element in the discourse is dependent on that of another. The one PRESUPPOSES the other, in the sense that it cannot be effectively decoded except by recourse to it. When this happens, a relation of cohesion is set up, and the two elements, the presupposing and the presupposed, are thereby at least potentially integrated into a text.
\end{abstract}

Los elementos que fungen como marcas de cohesión en la lengua sirven, por ende, para indicar la conexión entre las porciones del discurso, los contenidos, los temas, las referencias, etc. y como instrucciones interpretativas de búsqueda de cómo ha de procesarse el material lingüístico en relación con datos provenientes del contexto o del texto mismo; por ejemplo, en cuanto al antecedente de un pronombre. La cohesión, por consiguiente, encuentra su lugar en el plano interno del texto (cfs. Charaudeau y Maingueneau 2005).

Halliday y Hasan (1993) sostienen que la cohesión forma parte del sistema lingüístico; constituye un conjunto de recursos sistemáticos con los que cuenta la lengua misma para establecer relaciones entre los diversos elementos que componen el discurso. No obstante, en su uso del término, la cohesión es una relación semántica entre un elemento textual y otro rubro que es fundamental para la interpretación (decodificación) del primero y que también se encuentra en el mismo texto, independientemente de la estructura oracional en la que aparecen.

Por su parte, para de Beaugrande y Dressler (1997), los textos son un tipo de sistema y, como tales, hacen depender su estabilidad en la continuidad de los elementos integrativos; esto es, existen unos rubros que permiten acceder a otros rubros dentro de un mismo texto, en vista de que están vinculados. La continuidad parte del presupuesto de la existencia de una conexión entre los elementos linguísticos que conforman el mensaje y la situación comunicativa; en otras palabras, todo elemento funciona como mecanismo para tener acceso a otros elementos dentro del discurso. Así, por ejemplo, estos lingüistas conciben la sintaxis como un sistema especializado en establecer patrones de organización en la superficie textual.

Desde su perspectiva cognoscitiva, la cohesión tiene que ver con mecanismos relativos al almacenamiento de la información y la restringida capacidad de la memoria operativa para guardar materiales lingüísticos extensos durante el tiempo necesario para operar con ellos. Tales materiales, por lo general, pasan por un proceso denominado almacenamiento activo en la memoria operativa, por medio del cual se procesan y se "distribuyen entre los recursos cognitivos disponibles de acuerdo con la importancia que se les haya adjudicado a cada uno de ellos" (de Beaugrande y Dressler 1997:89). Luego, se elabora una memoria temporal que permite retener los materiales por mayor tiempo.

Para el receptor del texto, estas marcas formales permiten que las referencias se mantengan activas y, a la vez, se evita estar repitiendo las mismas palabras y las mismas estructuras al recurrir, por ejemplo, a un pronombre que recuerde la información ya introducida. En gran medida, la función comunicativa de la llamada concordancia (sujeto-verbo, sustantivodeterminantes, sustantivo-adjetivo, etc.) y, en general, de la gramática consiste, desde la perspectiva de la lingüística del texto, en mantener la cohesión.

De este modo, las estructuras sintácticas sirven el propósito de proveer esquemas estructurales limitados, en contraste con los conceptos y las relaciones, y restringen las opciones y los patrones del discurso, además de aligerar la carga de retención:

Debido a que las dependencias gramaticales se establecen a menudo entre elementos que aparecen alejados discursivamente unos de otros (...), la sintaxis ha de proporcionar patrones homogéneos de varios tipos y de diferentes grados de complejidad en los cuales puedan acomodarse los materiales 
reales. De ahí que las unidades sintácticas principales sean patrones de dependencias bien marcadas (...) (de Beaugrande y Dressler 1997:90).

Las unidades sintácticas básicas tienen en común la capacidad de ser procesadas en poco tiempo, mientras que para otras porciones textuales se requiere recurrir a procedimientos de reutilización, modificación o comprensión de los patrones y estructuras previos:

\footnotetext{
(...) clause structure is peculiarly adapted to representing certain kinds of perceived or imagined experience. Experience is too rich to deal with in total. People attend to certain bits of it and make sense of these. The world sketches that speakers draw are highly schematized and artfully constructed representations of experience. Among the percepts and concepts that are essential for making sense of experience, in human terms, are complex ones that may be called "events" and "situations". Clause structure is designed to allow people to specify the structure of (perceived) events and situations, to break them down into conceptual elements and spell out relationships between the elements; that is, clauses are devices for saying who did what, with which, to whom, and the like (Pawley y Hodgetts 2000:196).
}

Las lenguas naturales poseen recursos léxicos y gramaticales para expresar la cohesión textual. Los procedimientos gramaticales son recursos especializados en indicar que el oyente/ lector debe buscar la referencia en otro elemento textual y sirven el propósito de descargar el texto de formas de contenido semántico pleno y hacerlo más "liviano" por medio de la señalización de que determinadas entidades discursivas se repiten a través de ciertas marcas, como la concordancia.

Lo más importante, en relación con estos elementos gramaticales, es su estrecha relación con lo que se conoce como referencia, fenómeno en el cual la información que debe recuperarse es el significado referencial (la entidad a la que nos estamos refiriendo). Así, la cohesión se encarga de la continuidad de la referencia, en los casos en los que la misma entidad entre en el discurso más de una vez (Halliday y Hasan 1993:31). La referencia constituye una relación semántica, no gramatical; por ello mismo, los rubros correferenciales no tienen por qué ser de la misma categoría gramatical.

De este modo, pese a que muchas veces parezca una marcación redundante, la concordancia cumple una función cohesiva de aclaración de a cuál referente discursivo pertenecen las propiedades (en el caso de los adjetivos y determinantes) que se señalan, cuál es la identidad del referente que se recupera por medio de un pronombre, o a cuál elemento se le asigna la función de Sujeto, como se aprecia en los siguientes ejemplos proporcionados por Rabanales (1992): Se trata de la copia de un documento autorizada legalmente frente a Se trata de la copia de un documento autorizado legalmente, y de No respetó el cambio de dirección acordado frente a No respetó el cambio de dirección acordada.

Hemos de partir, por lo tanto, de que la concordancia cumple una función dentro de la lengua; existe una razón por la cual surgió. Si bien algunas veces parece ser una simple redundancia en términos ideacionales (basta que el contenido 'plural' se marque en el sustantivo, como lo hacen muchas lenguas, sin necesidad de manifestarse también en los otros elementos que se refieren a este), no lo es en cuanto a la metafunción textual, pues de la concordancia depende muchas veces la identificación de los referentes discursivos (como en el caso de los pronombres) y la correcta interpretación de a cuál referente se le ha de asignar, por ejemplo, determinada propiedad (codificada en un adjetivo), como se aprecia en los ejemplos tomados de Rabanales (1992).

Sin lugar a dudas, esta forma de describir la gramática resulta más compleja que la tradicional de elaborar reglas globales y totalmente sistemáticas a partir de porciones textuales pequeñas ('oraciones', en la nomenclatura usual), descontextualizadas y alejadas del uso 
cotidiano de los hablantes. No obstante, como se sostiene en la lingüística funcional sistémica (Halliday 2004), el objetivo de una descripción gramatical consiste en detallar y explicar los recursos para crear significado con que cuenta la lengua; si el modelo parece complejo se debe a que la gramática es intrínsecamente compleja, pues solo de esta forma puede cumplir su misión de servir a los hablantes para codificar los significados que se requieren.

Volviendo al asunto de los sustantivos colectivos, el primer paso consiste en reconocer que el sentido de 'colectividad' se relaciona con el de 'genérico', referido este al empleo de un sustantivo para aducir a una categoría. Ambos comparten el rasgo semántico de pluralidad, de conjunto de elementos de la misma clase. Difieren, sin embargo, en que el primero siempre es un sustantivo morfológicamente singular con significado plural referido a un conjunto, mientras el segundo es un sustantivo singular o plural que puede codificar tanto una entidad individual o grupo de individuos (sentido no genérico) o un conjunto de individuos que comparten determinadas propiedades que los hacen pertenecer a la misma categoría (sentido genérico). Por ejemplo, 'gente' es un sustantivo colectivo (siempre significa una pluralidad, aunque su forma no lo evidencie), mientras que 'niño' puede funcionar en el discurso tanto como sustantivo individual ('un niño determinado') así como sustantivo genérico (la categoría de los 'niños'), como se observa en los siguientes ejemplos:

\section{El niño hizo la tarea}

\section{El niño debe ser el fin último de la pedagogía}

Cuando un sustantivo individual adquiere un sentido genérico en un texto, los elementos que concuerdan con él manifiestan morfológicamente a veces la pluralidad, pues la concordancia se establece en función de recuperar el sentido de 'grupo' involucrado en el uso genérico. Estaríamos, por consiguiente, ante una concordancia semántica y no morfológica. Resulta indispensable aquí, entonces, comprender que la concordancia sirve una función textual cohesiva, en la que lo importante es posibilitar al máximo la identificación del referente discursivo y las propiedades fundamentales de este, en particular, su sentido de 'genérico'. Por ello mismo, no resulta adecuado hablar de discordancia en este caso, pues se estaría privilegiando la forma, separada del significado, y esta no es la manera en que la lengua constituye su arquitectura. Obsérvese el siguiente fragmento registrado en nuestro corpus:

- ¿Cómo se muestra respeto para con los hijos?

- Bueno, yo diría que el respeto comienza por... por uno mismo, por la firmeza en el carácter, en las posiciones y en las decisiones que tenga uno. Ahí comienza, verdad. Y luego, este... tratando de conocer al hijo, de impulsarlo en los gustos de él, en no tratar de... de... digamos, de manifestarse uno a través de ellos o de manifestar los fracasos que uno ha tenido a través de ellos sino más bien resaltando las... las características de su personalidad pero como individuales y propias. Entonces con eso, digamos, tratando de que ellos sean independientes y a su vez enseñarles eh...digamos, los condicionamientos o las normas que deben cumplir dentro de la comunidad porque ellos tienen también que aprender a respetar a los demás. No solo es que yo le enseñe al hijo a... el respeto a través de mí misma sino que ellos aprendan a respetar a los demás.

Se nota cómo el sustantivo 'hijo' se emplea con sentido genérico (evidente incluso en la forma plural como lo dice el entrevistador), lo que motiva que adquiera un sentido plural. Los primeros dos pronombres que entablan una relación de correferencialidad con este aparecen en 
singular morfológico también, pero los demás toman la forma plural. Debe entenderse, por ende, que los dos primeros también son genéricos y que manifiestan una concordancia que atiende a la morfología del sustantivo correferencial, pero luego, en el transcurrir del flujo informativo, la concordancia de los demás pronombres recupera, y manifiesta morfológicamente, el contenido de 'pluralidad' del genérico. La conclusión debe ser, como consecuencia, que la concordancia se construye textualmente, pues su función corresponde a la de codificar los contenidos que el hablante considera pertinentes conforme avanza en el proceso de elaboración de su discurso.

De este modo, tras analizar las posibles concordancias semántico-morfológicas que se entablan en porciones textuales más extensas que la oración en el caso de los usos genéricos de los sustantivos individuales, podemos ahora pasar a describir con mayor facilidad el fenómeno de la concordancia ad sensum de los sustantivos colectivos. En nuestro corpus, al igual que sucedió con los materiales analizados por Millán (1977), 'gente' es el sustantivo colectivo que aparece más habitualmente y con el que se establecen relaciones de concordancia más diversas. A este respecto, contabilizamos 119 apariciones de 'gente' en las que se produce una relación de concordancia con algún otro elemento. El siguiente cuadro resume los entornos en los que aparece en cuanto a la concordancia de la categoría de número; la categoría de género no se incluye, pues los datos son exiguos.

\section{Cuadro 1.}

Entornos sintácticos en los que aparece 'gente' con relaciones de concordancia

\begin{tabular}{lcc}
\hline Entorno sintáctico & $\begin{array}{c}\text { Concordancia } \\
\text { morfológica } \\
\text { (en singular) }\end{array}$ & $\begin{array}{c}\text { Concordancia } \\
\text { semántica } \\
\text { (en plural) }\end{array}$ \\
\hline
\end{tabular}

Elementos con relación de concordancia con

'gente' adyacentes o en la misma cláusula

$38 / 93 \%$

$3 / 7 \%$

41

'gente' adyacentes o en la misma clánsula

Elementos con relación de concordancia en una

cláusula de relativo con 'gente' como antecedente

$26 / 87 \%$

$4 / 13 \%$

30

Elementos con relación de concordancia con 'gente' separados por incisos de diverso tipo no clausales

$\begin{array}{lll}4 / 100 \% & 0 & 4\end{array}$

Elementos con relación de concordancia con 'gente' separados por incisos clausales

$7 / 88 \% \%$

$1 / 12 \%$

8

Elementos con relación de concordancia con 'gente' en cláusulas distintas

$4 / 11 \%$

$32 / 89 \%$

36

Las condiciones para que aparezca una concordancia semántica con los sustantivos colectivos coinciden, en términos generales, con lo reseñado más arriba: es más común cuando entre el sustantivo y los elementos que se refieren a él media cierta distancia (Millán 1977, Martínez 2000) o cuando los elementos no pertenecen a la misma cláusula (Bello 1964). No 
obstante, el otro requisito mencionado por Bello no parece ser tal en nuestros datos: poco importa que el colectivo se refiera a un grupo de elementos de clase indeterminada o no; tampoco aplica necesariamente cuando se ha intercalado un inciso, como lo señala Martínez (2000).

Por lo común, cuando los elementos concordantes con 'gente' se encuentran adyacentes a este o en la misma cláusula, la concordancia se rige por criterios puramente morfológicos (93 por ciento de los casos), y de ahí que las categorías nominales aparezcan en singular y femenino, mientras el verbo se conjuga en singular, como se aprecia en los siguientes ejemplos:

O sea... la gente no aprecia, no necesariamente aprecia la Arquitectura. No la Arquitectura sino el Diseño. Es qué hace el arquitecto, ¿por qué? Porque mucha gente hace casas

Estamos en San Ramón, aquí, que es un pueblo, como digamos Liberia-Guanacaste-. Hay un poco-digamos- la gente-digamos-un poco más pueblerina, verdad.

Empero, no están ausentes los ejemplos de concordancias ad sensum en estos mismos entornos, si bien en mucha menor cuantía (7 por ciento de los casos):

Eso debían de ponerlo en programas de televisión para que la gente se enteren

Pero allá, la gente de allá están viendo a ver cómo destierran a esa gente porque, verdad, es algo terrible

$Y$ tenemos un problema que mucha gente pobre nos focalizan como... como una institución gratuita

El condicionamiento descrito por Millán (1977) en cuanto a que la concordancia semántica se suele producir especialmente cuando 'gente' funciona como antecedente de una cláusula de relativo no encuentra parangón en nuestro corpus, pues se producen en tal entorno sintagmático tanto concordancias morfológicas como semánticas. De hecho, la gran mayoría de las concordancias de la categoría de número son de tipo morfológico (87 por ciento de los casos):

La gente que está en Generales no conocía más... ni un poquito más de Artes

Observo gente muy jovencita que sale de la Universidad ahí, tonteando un poco

Y menos son los ejemplos (13 por ciento del total) en los que, en este tipo de entorno sintagmático, se produce una concordancia semántica:

Todos éramos, entre comillas, adultos, que sabíamos que queríamos estudiar Arquitectura, porque había gente de tercero o cuarto año de Civil que se cambiaron

La misma situación parece repetirse cuando entre el sustantivo 'gente' y los elementos concordantes se encuentra un inciso, sea este de naturaleza clausal o no. Cuando en la cláusula se inserta un inciso no clausal, todas las concordancias contabilizadas dentro del inciso se rigen por criterios morfológicos, aunque los datos son pocos (únicamente cuatro). En cuanto a la concordancia entre 'gente' y los elementos pertenecientes a la misma cláusula separados 
por el inciso, también la concordancia sigue el criterio morfológico mayoritariamente en nuestro corpus (88 por ciento de los casos). En el siguiente ejemplo, no solo concuerdan en singular los verbos que se hallan en el inciso, sino también los propios de las cláusulas que se interrumpieron:

Entonces diay... generalmente la gente que... que... que está dando clases -a no ser que tenga muy adentro la... la... la desesperación por... por sacar lo que tiene adentro- pinta muy poco, esculpe muy poco

Según se revela en nuestros datos, definitivamente el entorno sintáctico que motiva la concordancia semántica es el rebase de los límites intraclausales; es decir, cuando el sustantivo 'gente' y los elementos que concuerdan con este se ubican en cláusulas distintas y se establece, por tanto, una relación cohesiva de correferencialidad. En esta situación, el 89 por ciento de los casos aparecen en plural, con lo cual se muestra cómo el hablante se inclina por un criterio semántico para establecer la concordancia. En otras palabras, cuando se trata de mantener a la distancia la referencia discursiva, las marcas formales de concordancia tienden a recuperar el contenido de pluralidad inherente al sustantivo 'gente':

Bueno, después de que presentamos la ... la... la tesis tuvimos algunas reuniones con alguna gente de La Caja, verdad. Porque ellos estaban bastante interesados en la información este... que iba a salir de ahí

- Porque la compañía se fue y dejó a la gente así, sin trabajo y sin nada.

- ¡Ah sí! Exacto. Nada más les dejó un cheque de liquidación.

- Pero acá, donde no hay ningún otro lugar en donde esta gente vaya a recurrir focalizan hacia acá. Y tenemos un problema que mucha gente pobre nos focalizan como... como una institución gratuita. O sea, ni siquiera tienen la idea de que nos tienen que venir a pagar,

verdad. Entonces vienen sin plata...o vienen...

- Como si fueran de La Caja (risas).

- Sí vienen con esa idea de que vos les tenés que ayudar porque ellos tienen un problema. Pero no... no piensan en la otra parte de nosotros que es una consulta privada. Pero... este... porque no tienen adónde canalizar el problema.

Ahora yo siento que la gente que está criando adolescentes eso es lo que los tiene más asustados

Hay gente que no. No logran cerrar una negociación. Claro que cuando vos construís siempre generás problemas: más caro todo, no era lo que habías pensado, hay gente que no te interpreta planos... Pero después de un año, en un abrir y cerrar de ojos, te vuelven a llamar. Porque en el fondo se dieron cuenta que lo que lo que había pasado al calor de... de la construcción, no era tan importante.

Cabe anotar que muchas veces el sustantivo 'gente' presenta la particularidad de servir como mecanismo de indiferenciación referencial, como un recurso para generalizar algo con respecto a un colectivo humano. De este modo, el hablante lo utiliza como estrategia para referirse a una entidad vaga, sin una especificidad concreta, lo cual lo acerca a otros recursos 
sintácticos con que cuenta el español para la expresión de la inespecificidad, tales como las cláusulas impersonales con el clítico 'se', las impersonales con el pronombre 'uno' y las llamadas impersonales eventuales (con verbo en tercera persona plural y sin sujeto expreso). En particular, la cercanía entre las construcciones con 'gente' como referente discursivo principal y las cláusulas impersonales eventuales resulta evidente, lo que nos lleva a pensar que, con toda probabilidad, a veces también se produce una especie de alternancia entre construcciones con el sustantivo 'gente' y construcciones impersonales eventuales, como se aprecia en los siguientes ejemplos:

Hay que ver la gente que va a ver esas exposiciones... Toda la crema y nata. $Y$ van a comprar. Y los precios... Diay, ¿qué le digo? Si yo en mi nivel vendo una acuarela en cinco mil pesos y me la compran

- Lo matan y la gente sigue caminando así: 'Ah. Mirá, le cortaron la cabeza a ese señor.' (risas)

- Mjm.

- Y siguen caminando. Entonces la gente se va deshumanizando.

- ¿Y eso no tendrá que ver con la televisión?

- Sí, tiene que ver con la televisión y también con... con el ritmo que exige el mundo actual. Es que...

- No pero así, es que digo yo que ven tanta violencia y la gente se acostumbra a ver violencia en la televisión.

- La televisión influye mucho. Sí es cierto. En un chiquito, digamos.

- Porque para nosotros no era lógico eso, no era posible: ver a una persona herida o mal y pasar recto.

- Sí.

- Pero ahora ya es normal.

- Bueno eso es una causa de la televisión. Sí-digamos- una causa que la gente se haya... se haya despreocupado. Ahora, lo que pienso yo es que la... la misma actitud de las personas (...). O sea: 'Si yo me involucro, después me matan a mí también. Mejor me quedo quedito y sigo adelante'. En... la gente no sé, diay, como que ha perdido la... la noción de que tal vez la unión hace la fuerza. O sea, si llega un maleante y lo agarran entre cinco ahí (...) el maleante va a salir perdiendo, verdad. Pero la gente como... al perder esa unión, por la misma despersonalización que existe, se... no le interesa ni lo que le pasó a usted.

- Ni lo conozco, ni de dónde viene.

- Ni lo conozco. Entonces... diay no. Diay si usted... Si uno ve un problema social que atañe aquí a Costa Rica sería en unos... a unos años, no sé ni cuándo, que la leche aumentaba un cinco y la gente hacía un escándalo. Se iba a las calles y todo. Había un poco de unión. Y ya la cantidad de gente... y ahora la leche la liberaron, aumenta un cuatro cada quince días y la gente no dice nada. Y no es que la gente tiene plata porque la gente no tiene plata. Tal vez tengamos plata, diay, los profesionales y cuando menos tenemos un nivel de vida aceptable. Pero hay gente que no, que no puede...

- Que no puede pagar la leche con esos precios.

- Que no puede pagar la leche a esos precios. Pero sin embargo no dicen nada. 
Aunque también aparecen concordancias atenidas a la morfología singular del sustantivo 'gente' a la distancia, en cláusulas distintas, tales casos son numéricamente escasos (un 11 por ciento de nuestros datos):

$Y$ vino gente de Parques Nacionales, evaluó el área y dijo que sí, que reunía una serie de condiciones para... para hacerla área educativa y recreativa.

Con respecto a otros sustantivos colectivos, nuestros datos son demasiado exiguos como para permitir un análisis pormenorizado; empero, todo apunta a que los mismos condicionamientos ya descritos funcionan para otros casos, como se puede observar en los siguientes ejemplos con los colectivos 'personal' y 'familia':

Pero me da la impresión de que el personal se resiste, ¿no?, se defiende. Aunque tenga... o estén en crisis o sientan tensión, me da la impresión de que el tipo de gente que hay aqui en esta institución, verdad, que es de muy alto nivel, ¿no se resisten así... a ir a consulta, así?

No, mi familia me lo recordó muchas veces. Yo no sé si... No, que tenían toda la razón obviamente

La concordancia ad sensum afecta asimismo otros sustantivos cuyo contenido es más o menos tan difuso o poco específico como 'gente' y se emplean igualmente como un recurso de indiferenciación referencial. Si bien los casos que aparecen en nuestro corpus son muy escasos, se puede percibir que su comportamiento no difiere de lo ya descrito en cuanto a que la concordancia morfológica (en género y número) se prefiere cuando los elementos en cuestión se encuentran cercanos o en la misma cláusula, mientras que la concordancia semántica prima cuando media la distancia o la membrecía a cláusulas distintas y el hablante recupera gramaticalmente más bien la identidad del referente discursivo en términos de contenidos intrínsecos al sustantivo y no partiendo de lo que se expresa formalmente.

En este sentido, el sustantivo 'persona' resulta particularmente llamativo, pues también constituye un recurso para referirse a una entidad indeterminada y, usualmente, colectiva, al asumir frecuentes funciones genéricas en el discurso. Cuando esto sucede, la concordancia se produce en singular y femenino si los elementos se hallan cerca, o en plural y facultativamente en masculino cuando se trata de cláusulas distintas:

Yo diría que el respeto va aparejado con... con el conocimiento que tengamos nosotros de cada persona con la que tenemos que relacionarnos y sobre todo, este... de aceptarlos. De aceptarlos así como son, verdad

El pronombre indefinido 'alguien' también presenta un comportamiento particular en cuanto al fenómeno de la concordancia. Nuevamente, nuestros datos son escasos, pero, a juzgar por lo que registramos, el establecimiento de la concordancia según parámetros morfológicos o semánticos actúa de acuerdo a la distancia sintáctica, como lo hemos descrito más arriba. Cabe resaltar, por lo demás, el carácter evidentemente impersonal que adquiere esta construcción y, por consiguiente, su alternancia con las cláusulas impersonales eventuales:

O yo diría que alguien me falta el respeto cuando me dicen alguna vulgaridad cuando yo voy por la calle. $O$ cuando... este... eh... me tratan mal, digamos en... en un cierto medio 


\section{La concordancia con grupos nominales complejos}

No resulta infrecuente encontrar afirmaciones de que en estilos de habla cuidadosos o formales está ausente la concordancia ad sensum. Así, por ejemplo, Alcina y Blecua (1994) señalan la existencia de construcciones del tipo "un grupo de amigos estaban...", en el que el verbo concuerda en plural con el complemento de sustantivo 'de amigos' y no con el núcleo del sujeto 'un grupo', pero aseveran que el uso cuidado rehúye tal construcción. Empero, las gramáticas suelen recoger este tipo de concordancia y señalar que es muy habitual.

Es claro que el verbo en español concierta en número y persona con el Sujeto de la cláusula $^{1}$, a pesar de que -como se vio en el apartado anterior- esa concordancia puede atender a dos criterios, dependiendo especialmente de la distancia sintáctica: la forma (concordancia morfológica) o el sentido (concordancia semántica). Por consiguiente, para comprender el funcionamiento de la concordancia en los casos que nos conciernen aquí, se requiere analizar la composición de los grupos nominales complejos.

Según el marco sistémico-funcional, la estructura experiencial (metafunción ideacional) del grupo nominal incluye como constituyente central el elemento Cosa, función que puede ser cumplida por un sustantivo común, un nombre propio o un pronombre personal, y que codifica las entidades a las que se refiere el discurso. Otros elementos lo acompañan y codifican significados específicos: Deícticos, Calificadores, Clasificadores, etc. Precisamente, en términos de morfología flexiva, estos otros constituyentes del grupo nominal muestran concordancia formal con el sustantivo que funciona como Cosa, en vista de que este es el centro del grupo nominal.

Por otra parte, la estructura lógica (representación de las relaciones lógico-semánticas) del grupo nominal se refiere a su composición con un elemento central, la Cabeza, y los modificadores de este (Premodificadores y Posmodificadores) vistos como un todo. Así, la Cabeza y la Cosa suelen coincidir, como en el ejemplo "La casa amarilla", pero en determinadas construcciones otro elemento de la estructura experiencial puede ocupar la posición de Cabeza (como en los casos de elipsis: "La amarilla").

También es posible que ambos elementos estén presentes pero disociados, cuando se inserta un elemento premodificador que en sí mismo es un grupo nominal, por lo que el elemento Cosa queda incluido en una frase preposicional, como en "Una caja de leche". En este último caso, el constituyente Cabeza puede solaparse con cualquiera de las funciones premodificadoras. De todas ellas, la que nos interesa es la función de Clasificador, la cual especifica una subclase particular de la entidad en cuestión (como el tipo de relación entre la Cabeza y la Cosa: colectivo, partitivo, cuantitativo). En estas construcciones, es el elemento Cosa el que realmente funciona como participante en la cláusula (metafunción experiencial), mientras la Cabeza es la que suele funcionar como Sujeto (metafunción interpersonal) (Halliday 2004).

Precisamente, nuestra posición es que esta disociación entre el elemento Cosa y el elemento Cabeza provoca que la concordancia pueda realizarse, en determinadas ocasiones, a partir de dos criterios, como ya se ha expuesto con los sustantivos colectivos: un criterio formal (concordancia con el elemento Cabeza, que suele funcionar como Sujeto) y un criterio semántico (concordancia con el elemento Cosa).

En nuestro corpus, los grupos nominales que aparecen con más frecuencia con la doble concordancia son: la mayoría de..., un montón de..., una serie de..., (elleselestelqué) tipo de..., y la mayor parte de..., seguidos por un sustantivo en plural, que cumple la función de Cosa. A todas luces, se trata de construcciones partitivas, como lo sostiene Martínez (2000). 
En el caso de las construcciones la mayoría de... y la mayor parte de..., en nuestros datos es prácticamente absoluta la concordancia ad sensum. En nuestros ejemplos, el elemento Cosa por lo general es una entidad humana, lo cual contribuye probablemente para que la concordancia se establezca con este segundo elemento:

Y... y con el agravante de que la inmensa mayoría de los padres de familia, ¿qué es lo que ven en el televisor?

La mayoría de los chiquitos les tienen pánico

Sí yo recuerdo...yo recuerdo la mayoría de los colegios llevaban uniforme

La mayoría de las pacientes son de embarazo de alto riesgo

La mayoría de las mujeres clasifican en embarazo de alto riesgo

Yo diría que la mayor parte de los costarricenses no... no consumen, no comen mejillones

Se dará un caso parecido, por ejemplo, a la odontología en que la mayor parte de los especialistas prefieren quedarse aquí en la capital

Nótese cómo en el siguiente ejemplo la concordancia con el elemento Cabeza ('la mayoría') sería agramatical. Se trata de una cláusula en la que se ha colocado el Complemento en posición preverbal, lo que provoca que, al ser este humano y específico, se reduplique por medio de un pronombre átono, como es lo normal en español moderno. Sin embargo, dicho pronombre 'los' concuerda en género y número con 'los niños' y no con 'la mayoría'; lo contrario, es decir la concordancia con 'la mayoría', parece inadmisible:

Las bombetas a la mayoría de los niños los amenaza mucho

\section{* Las bombetas a la mayoría de los niños la amenaza mucho}

Las construcciones una serie de + sustantivo plural y un montón de + sustantivo plural, al igual que las anteriores, suelen aparecer con concordancia ad sensum. Se trata de Clasificadores cuantitativos indefinidos, equivalentes a 'un grupo de' o 'un conjunto de':

Se identifican las especies y luego uno hace una consulta de la flora, de las diferentes floras y ahí vienen una serie de datos y entre esos datos aparecen cosas interesantes (4)

Entonces de ese sendero van a salir una serie de senderos que llamamos "senderos demostrativos" que van a ir pasando por... por los... diferentes árboles

En un determinado período de gobierno se hicieron una serie de préstamos de corto plazo a altos intereses

Una serie de educadores que comprendieron que era importante que la educación... que los maestros se formaran en un plantel propio para ellos 
Te decía que... que cuando uno sale de la carrera uno encuentra que hay un montón de lagunas que uno dice pero por qué no me las llenaron, verdad

Como todos son un puño de idealistas solo ponen un montón de ideas que no tienen ningún contenido ni relación con la realidad

Entonces este montón de chiquitas de ahora vos las ves donde... donde... donde le... le... le... les coquetean descaradamente a los chiquillos, a los varoncillos

El siguiente ejemplo reafirma el peso de la concordancia semántica en español. Estamos ante un caso en el que el verbo de la cláusula de relativo se dice en plural por concordancia ad sensum con el colectivo 'gente':

Porque ahora llega uno y se encuentra un montón de gente joven que dicen: ‘Ay! Estoy pensionada'.

La construcción un/el tipo de... funciona asimismo como un Clasificador de generalización y también es frecuente que la concordancia se establezca con el elemento Cosa y no con la Cabeza ('tipo'):

¿Hay diferencia en el tipo de pacientes que llegan a cada una de las clínicas?

yo siento que este tipo de becas y de programas son como para "amaestrar"

Las posibilidades de que este tipo de cosas sucedan se potencian en la medida que quien es irrespetado también irrespeta al otro

A ver qué se puede hacer, qué se puede a... qué tipo de proyectos se pueden realizar allá. Qué tipo de acciones se pueden llevar a cabo. Qué tipo de trabajos o qué actividades se pueden desarrollar

La tendencia se repite con otras construcciones del mismo tipo que aparecen en poca cuantía en nuestro corpus:

Ahí se ven todavía la partida de vagabundos, ahí. Pierden los años por ir a ver las 'salidas del Seño'

Sin embargo un par de personas que resultaron con e... heridas leves, pues, rasponazos en las piedras

Como queda dicho, por ende, la concordancia en este tipo de construcciones suele atenerse a criterios semánticos, según los cuales el elemento rector que establece la concordancia es el elemento Cosa, pues es realmente la codificación de la entidad de la que se habla en el discurso. El sustantivo que funciona como Cabeza cumple la función de indicar la clase o tipo en el que se inserta esa entidad plural o de cuantificarla de modo indefinido. 


\section{Conclusiones y consideraciones en cuanto a la enseñanza del español}

La concordancia en español, en sus diversas manifestaciones (de los nominales con respecto al sustantivo, o del verbo con respecto al Sujeto), no es simplemente un fenómeno de redundancia en la lengua, aunque muchas veces así lo parezca. Tampoco se trata de un simple mecanismo desambiguador, como lo llama Rabanales (1992). Como se ha mostrado, la concordancia se inserta dentro de los mecanismos de construcción textual de la lengua y responde a la necesidad de mantener y aclarar la identidad de los referentes discursivos. Por consiguiente, habrá que aceptar la idea de que la concordancia se construye discursivamente.

Halliday (2004) postula que la lengua es tanto virtualidad como concreción. La gramática, entonces, es un sistema potencial que sirve de fuente para crear significado, con reglas de funcionamiento constantes y predecibles, pero la lengua también es un conjunto de textos, una manifestación comunicativa que pone en marcha tal potencialidad y la hace patente cada vez que un hablante recurre a ella en una situación de habla específica. Así las cosas, no podemos conformarnos con descripciones morfosintácticas que se queden solo en la potencialidad, en el sistema esperable y altamente regularizado.

Si hemos de pretender que nuestra aproximación al funcionamiento de la lengua sea lo más completo posible, debemos emprender la tarea de analizar la realización de ese sistema, su empleo en discursos reales; en última instancia: su materialización. Si procedemos de este modo, contaremos con descripciones más exhaustivas y verídicas de la morfosintaxis del español. Asimismo, entenderemos que los fenómenos de la gramática de la lengua se construyen en el proceso de producción textual; no están dados previamente más que como un conjunto de posibilidades de entre las cuales el hablante escoge las que más le convienen en un momento dado. La concordancia ad sensum que tratamos en este artículo es buena muestra de ello.

La concordancia semántica no se debe a un descuido, no es producto de la falta de atención o de la impericia del hablante, como se deja entrever en lo que se dice en muchas gramáticas del español. Constituye, por el contrario, una posibilidad del sistema y, como tal, una opción disponible para los hablantes para entablar las conexiones necesarias con el fin de cohesionar sus intervenciones discursivas.

Así las cosas, sin duda habrá que revisar la forma en que se enseña el español como idioma materno y segunda lengua, prácticas ambas ceñidas normalmente a las descripciones simplistas y reduccionistas de la gramática normativa tradicional.

En el caso de la didáctica de la lengua materna, particularmente en lo que respecta a la destreza de producción escrita, se suele insistir en las reglas de concordancia de forma descontextualizada, utilizando como modelos oraciones inconexas, y dejando la idea de que se trata de una exigencia formal de la lengua que no cumple ningún propósito. La presentación de la teoría nunca muestra la concordancia como un mecanismo cohesivo y, por lo tanto, se pierde la razón de ser de estudiar este contenido en un curso de expresión escrita.

En el peor de los casos, inclusive se califica de incorrecciones formas como la siguiente: "Se miraban en la lejanía una cantidad de jóvenes" y se propone en su lugar "Se miraba en la lejanía una cantidad de jóvenes", pero luego se afirma que en el siguiente ejemplo ambas concordancias son correctas: "Un grupo de niños estaba (estaban) gritando" (Pacheco y Álvarez 2000). El desconcierto del aprendiz ante una regla que se contradice en los ejemplos es más que comprensible, así como lo es cuando la explicación es tan oscura como la siguiente: 


\begin{abstract}
El sujeto colectivo homogéneo, aunque esté formado por un núcleo singular que reúna varios elementos, siempre utiliza el verbo en singular. Sin embargo, en el momento de redactar o hablar, la persona puede valerse del verbo para enfatizar el carácter que le está dando el sujeto.

De manera que dentro de un contexto, las (sic) misma oración puede tener un carácter heterogéneo, también. Un grupo de estudiantes de la U.C.R., U.N.E.D. y U.N.A. se reunió para dialogar.

Esta oración adquiere el carácter heterogéneo, si se pretende establecer que los elementos reunidos corresponden a especies distintas: universidad estatal y privada. Entonces acepta el verbo en plural (Pazos 2001:72-72).
\end{abstract}

Poco provecho obtendrá un estudiante al que se le muestren tales explicaciones. Si su expresión escrita mejora, no será gracias a un curso que le proporcione tales reglas y ejemplos, sino que la mejoría se habrá producido pese a este. Al igual que todos los contenidos lingüísticos de los cursos de lengua materna, la enseñanza de la concordancia debe reconceptualizarse. Si no se concibe como un recurso cohesivo, no tiene ninguna trascendencia su incorporación al curso. Y si se incluye como estrategia discursiva, ha de estudiarse entonces como un mecanismo sujeto a variaciones que dependen del proceso de construcción textual, como claramente se observa en el caso de la concordancia ad sensum.

La enseñanza del español como segunda lengua tampoco escapa a los desaciertos de la didáctica de la lengua materna. Por lo general, se insiste en la enseñanza de la concordancia como una serie de reglas descontextualizadas y simplistas, en las que, por supuesta economía didáctica, no se dice toda la verdad con respecto a la lengua. A este respecto, lo común es encontrar reglas como la siguiente: "el sustantivo 'gente' en español siempre lleva verbo en singular, no como en inglés o francés". Si bien es cierto que construcciones como "La gente son muy simpáticas", común por interferencia del inglés en boca de angloparlantes aprendices de español, no son tan habituales ${ }^{2}$, se ha mostrado en este artículo cómo la concordancia con el verbo en plural es completamente normal bajo ciertas circunstancias sintáctico-textuales. De hecho, tal concordancia no es solo común, sino incluso lo esperable en muchos casos. Por ende, habrá que trascender los límites de la enseñanza de la gramática a partir de oraciones e incorporar con regularidad al menos el input de fragmentos textuales, en los que se aprecie el empleo de la gramática en el discurso real espontáneo. Así, las reglas pedagógicas puede ser que pierdan en simplicidad, pero al menos ganan en utilidad y apego a la realidad de la comunicación lingüística.

En suma, estudiar gramática, con fines teórico-descriptivos o aplicados a la didáctica de la lengua, es una actividad que debe reconocer la doble naturaleza del lenguaje: como texto y como sistema, tal y como lo señala el mismo Halliday:

As grammarians we have to be able to shift our perspective, observing now from the system standpoint and now from that of the text; and we have to be aware at which point we are standing at any time (...). Writing a description of a grammar entails constant shunting between the perspective of the system and the perspective of the instance" (Halliday 2004: 29).

\title{
Notas
}

1. Por razones de facilidad expositiva, hemos venido utilizando etiquetas como 'verbo' y 'Sujeto', las cuales, como se detalla en Halliday (2004), son de distinta naturaleza: 'verbo' se refiere a una clase, una categoría de palabras, mientras 'Sujeto' es una función dentro de la estructura interpersonal de la cláusula. De ser rigurosos con la terminología de la escuela sistémica, nos referiríamos a los verbos con el nombre correspondiente a la función que desempeñan también en la estructura interpersonal, a saber: 
Predicadores. Hemos evitado tal proceder (y, como consecuencia, seguido una línea más cercana a la nomenclatura de la gramática tradicional) con el fin de hacer más sencillo el análisis para el lector con poco contacto con la teoría hallidiana.

A excepción, posiblemente, del español cubano, en cuyo caso es común escuchar tales construcciones (observación personal).

\section{Bibliografía}

Alarcos Llorach, Emilio. 2000. Gramática de la lengua española. Madrid: Espasa-Calpe.

Alcina Franch, Juan y José Manuel Blecua. 1994. Gramática española. Barcelona: Ariel.

Bello, Andrés. 1964. Gramática de la lengua castellana. Buenos Aires: Editorial Sopena.

Calsamiglia Blancafort, Helena y Amparo Tusón Valls. 2002. Las cosas del decir. Manual de análisis del discurso. Barcelona: Ariel.

Charaudeau, Patrick y Dominique Maingueneau. 2005. Diccionario de análisis del discurso. Buenos Aires: Amorrortu.

De Beaugrande, Robert-Alain y Wolfgag Ulrich Dressler. 1997. Introducción a la lingüística del texto. Barcelona: Ariel.

Gili Gaya, Samuel. 1980. Curso superior de sintaxis española. Barcelona: Bibliograf.

Halliday, M.A.K. y Ruqaiya Hasan. 1997. Cohesion in English. Nueva York: Longman.

Halliday, M.A.K. 2004. An Introduction to Functional Grammar. Nueva York: Oxford University Press.

Lewandowski, Theodor. 2000. Diccionario de Lingüística. Madrid: Cátedra.

Lope Blanch, Juan (ed.). 1977. Estudios sobre el español hablado en las principales ciudades de América. México: Universidad Nacional Autónoma de México.

Martínez, José Antonio. 2000. "La concordancia". En: Bosque, Ignacio y Violeta Demonte (dir.). Gramática descriptiva de la lengua española. Vol.2. Madrid: Espasa Calpe, 2695-2786.

Millán Orozco, Antonio. 1977. "Anomalías en la concordancia del nombre en el español de la Ciudad de México". En: Lope Blanch (ed.). 
Pacheco Salazar, Viria y María Angelina Álvarez Flores. 2000. Comunicación escrita y oral. San José: CQ Impresos, S.A.

Pazos, Éthel. 1996. Frecuentes errores del hispanohablante. San José: Editorial Alma Mater.

Rabanales, Ambrosio. 1992. Métodos probatorios en gramática científica. Madrid: Istmo.

Real Academia de la Lengua Española. 1976. Esbozo de una nueva gramática de la lengua española. Madrid: Espasa-Calpe.

Seco, Rafael. 1960. Manual de gramática española. Madrid: Aguilar.

Solano Rojas, Yamilet. 1989. El habla culta costarricense (Materiales para su estudio). México: UNAM. 